\title{
ÉDOUARD GLISSANT, Le Indie
}

\section{Carminella Biondi}

\section{OpenEdition \\ Journals}

\section{Édition électronique}

URL : https://journals.openedition.org/studifrancesi/45569

DOI : 10.4000/studifrancesi.45569

ISSN : 2421-5856

\section{Éditeur}

Rosenberg \& Sellier

\section{Édition imprimée}

Date de publication : 1 août 2021

Pagination : 416-417

ISSN : 0039-2944

\section{Référence électronique}

Carminella Biondi, « Édouard glissant, Le Indie », Studi Francesi [En ligne], 194 (LXV | II) | 2021, mis en ligne le 01 septembre 2021, consulté le 15 octobre 2022. URL : http://journals.openedition.org/ studifrancesi/45569; DOI : https://doi.org/10.4000/studifrancesi.45569

Ce document a été généré automatiquement le 15 octobre 2022.

\section{(c)}

Creative Commons - Attribution - Pas d'Utilisation Commerciale - Pas de Modification 4.0 International - CC BY-NC-ND 4.0

https://creativecommons.org/licenses/by-nc-nd/4.0/ 


\title{
ÉDOUARD GLISSANT, Le Indie
}

\author{
Carminella Biondi
}

\section{RÉFÉRENCE}

ÉDOUARD GLISSANT, Le Indie, traduzione e postfazione di A. Gazzoni, Roma, Edizioni

Ensemble, 2020, 109 pp.

1 Il y a eu, en Italie, une décennie féconde pour la réception de l'œuvre de Glissant, au début $d u x x^{\mathrm{e}}$ siècle, qui a vu paraître en traduction italienne trois romans et trois essais, entre 2003 et 2013, mais aussi de nombreuses études, des mémoires et des thèses de doctorat. En 2004 l'Université de Bologne lui a conféré la Laurea ad honorem. La décennie qui a suivi la mort de l'auteur a été moins généreuse et s'est bornée, dans le domaine de la traduction, à quelques fragments. C'est donc un véritable plaisir que de saluer ce retour qui, on l'espère, sera le signal d'une relance de l'œuvre de l'écrivain en Italie. Un retour qui est aussi une ouverture car personne n'avait eu, jusqu'à présent, le courage de s'engager dans la traduction d'un texte poétique (si ce n'est, on l'a dit, par fragments). Andrea Gazzoni a choisi, dans le florilège de la poésie glissantienne, le long poème Les Indes (1956), un poème épique en six chants (épique au sens glissantien de chant de «la rencontre, enfin des histoires des peuples», Introduction à une poétique du Divers, Gallimard, 1996, p. 79), poème ardu, dense d'événements car il entraîne dans son parcours vertigineux trois continents, l'Europe, l'Amérique et l'Afrique, au moment où leur rencontre bouleverse l'histoire du monde. Un poème séminal aussi, comme nous le rappelle le traducteur dans une postface (pour laquelle il choisit un titre qui nous implique: Le Indie, nostre) qui a le mérite de renfermer en quelques pages d'une efficacité remarquable, non seulement une introduction au poème, mais encore une synthèse éclairante, et séduisante, de l'ensemble de l'œuvre: «Le Indie è anche uno dei testi seminali di tutta la multiforme opera di Glissant, così varia eppure così inestricabilmente connessa in tutte le sue forme [...] il poema ha già in sé i motivi generatori di una poetica che egli ha continuato a dire, ridire, studiare, scandagliare, trasformare e verificare fino al 2011, anno della sua scomparsa» (p. 95). 
2 Malgré la difficulté de garder dans la traduction en même temps le ton épique et lyrique, et de ne pas céder à la tentation de faire violence à l'opacité, qui est la marque de l'écriture glissantienne, Andrea Gazzoni a réussi à faire passer dans le texte italien le souffle de cette immense épopée de la découverte, un événement grandiose qui a brassé les peuples, souvent en les déchirant, mais qui a ouvert à la «Relation» (c'est le titre du dernier chant du poème, et l'un des concepts fondateurs de la poétique glissantienne), synonyme d'ouverture à l'autre, dans une dynamique constante, spatiale et temporelle. L'Italie a un rôle important dans cette épopée, car le voyage vers les Indes (Indes réelles et Indes de rêve) commence à Gênes («Sur Gênes va s'ouvrir le pré des cloches d'aventures») et s'y conclut, dans un parcours initiatique en quête du monde à venir, un monde qui deviendra, plus tard, dans la réflexion de Glissant, le «Tout-monde».

3 Aux mérites de la postface dont j'ai déjà parlé, s'en ajoute un autre, celui de l'avoir conclue avec un texte qu'Armando Gnisci, maître du traducteur et «passeur» passionné de la parole glissantienne en Italie, a dédié à l'écrivain en 2014, Tombeau de Glissant, qui est devenu, entre temps, aussi un tombeau pour Gnisci (mort en 2019): «Se il 3 febbraio non fosse marcato dalla morte di Glissant, sarebbe un giorno dimenticato come tutti gli altri, in fondo alla tomba dell'indifferenziato, almeno per me. Era Glissant infatti, ed è, il mio maestro più potente del mondo» (p. 105). Merci à Andrea Gazzoni pour avoir pris la relève de son maître et pour continuer, selon les paroles de Glissant, à inventer «un langage nécessaire d'une langue à l'autre, comme le poète invente un langage dans sa propre langue. Une langue nécessaire d'une langue à l'autre, un langage commun aux deux, mais en quelques sorte imprévisible à chacune d'elles» (Glissant, Introduction à une poétique du Divers, p.45). Que l'éloge de la traduction de Glissant, en tant qu'instrument de créolisation et de Relation, et d'invention d'un langage de partage, lui soit ici dédié, comme viatique pour tant d'autres traductions glissantiennes à venir. 